\title{
Existence of non-trivial complex unit neighborhoods
}

\section{PABLO PINIELLA}

\begin{abstract}
.
First, we briefly mention the basic definitions and results on unit neighborhoods of zero. Next, we show the existence of certain non-trivial complex unit neighborhoods of zero. We expose a generalization of the construction method used on the mentioned particular case. Since this construction may not lead to a unit neighborhood of zero, we develop some necessary conditions. Finally, we describe our heuristic use of Wolfram Mathematica to prove the existence of non-trivial complex unit neighborhoods.
\end{abstract}

\section{REFERENCES}

[1] Abel, M., On splitting of extensions of rings and topological rings, Ann. Funct. Anal., 1 (2010), No. 1, 123-132

[2] Arnautov, V. I., Glavatsky, S. T. and Mikhalev, A. V., Introduction to the theory of topological rings and modules, Marcel Dekker, Inc., New York, 1996

[3] Arnautov, V. I., Properties of one-sided ideals of topological rings, Bul. Acad. Ştiinţe Repub. Mold. Mat., 29 (2006), No. 1, 3-14

[4] Bourbaki, N., Topological vector spaces. Chapters 1-5 Springer-Verlag, Berlin, 1987

[5] Costash, A. I. and Ursul, M. I., The group of units of a locally compact ring, Izv. Akad. Nauk Respus. Moldova Mat., (1996) No. 3 , 20-28

[6] García-Pacheco, F. J. and Piniella, P., Unit neighborhoods in topological rings, Banach J. Math. Anal., 9 (2015), No. 4, 234-242

[7] Kothe, G., Topological Vector Spaces I, Springer-Verlag, New York Inc, 1969

[8] Urbanik, K. and Wright, F. B., "Absolute-valued algebras" http://www.ams.org/journals/proc/1960-011-06/S0002-9939-1960-0120264-6/S0002-9939-1960-0120264-6.pdf Web 30/03/2014

[9] Ursul, M. I. and Martin, J., Notes on topological rings, Carpathian J. Math., 29 (2013), No. 2, 267-273

[10] Warner, S., Topological Fields, Elsevier Science Publishers B. V., Amsterdam, 1989

[11] Warner, S., Topological Rings, North-Holland Publishing Co., Amsterdam, 1993

DEPARTMENT OF MATHEMATICS

UNIVERSITY OF CÁDIZ

11510 PUERTO REAL, SPAIN

E-mail address: piniella5050@gmail.com

Received: 02.10.2015; In revised form: 08.01.2016; Accepted: 26.03.2016

2010 Mathematics Subject Classification. 16W80, 54H13, 46H25.

Key words and phrases. Complex numbers, topological ring, absolute semi-value, closed unit. 